Die Lage der „Förderungs“- und „Hemmungs“-Bezirke zeigt auch dann, wenn an Stelle der intensitätsgleichen, aber qualitativ erweiterten Strahlung des Differenzfilterverfahrens engere Bereiche verschiedener Wellenlänge in gleicher Intensität einwirken, eine überraschende $\mathrm{Be}$ ziehung zu den entsprechenden Bezirken der Licht-Keimung ${ }^{7}$. Gerade die Wellenbereiche, die bei der Keimung eine Förderung bedingen, erreichen bei der Atmung keine Stimulation des Dunkelwertes, während umgekehrt die Keimung hemmende Strahlen die Atmung zu steigern vermögen.

Eine theoretische Deutung dieser und anderer Ergebnisse sowie Fragen der Temperaturabhängigkeit der Lichtatmungsreaktion und ihre Beziehungen zum Lichtgenuß des Vorlebens bei farblosen Licht- und Dunkelgeweben wird der eine von uns (R os enstock) unter Vorlage eines reichen experimentellen Materials an anderer Stelle behandeln.

7 M e is chke, Jb. wiss. Bot. 83, 359 [1936].

\section{Zur Geschlechtsbestimmung mit Testosteron bei Erdkröten}

Von J. W. H a r ms*

(Z. Naturforschg. 5 b, 173 [1 155 ]; eingegangen am 23. Jan. 1950)

Vor 25 Jahren gelang es mir, erwachsene Erdkrötenmännchen in voll funktionsfähige Weibchen umzuwandeln, und zwar durch Exstirpation der Hoden und Umwandlung des Bidderschen Organs in ein Ovar. Eileiter und Uterus kamen daraufhin zur Entwicklung, und sogar die Körperform des Männchens, einschließlich des Schä-

* z. Zt. Marburg a. d. Lahn, Anatom. Institut der Universität. dels, wurden weiblich ${ }^{1}$. Bei Parallelversuchen am Weibchen entwickelte sich nach Ovarektomie aus dem Bidderschen Organ ein Ersatzovar.

Beim Bidderschen Organ handelt es sich um eine geschlechtlich noch nicht differenzierte Keimdrüse, bei der man feststellen könnte, ob die Geschlechtshormone auf sie als Termone wirken können. Wir haben solche Versuche in Angriff genommen, die bisher noch nicht abgeschlossen werden konnten.

Im Juni und Juli 1949 wurden bei erwachsenen Männchen und Weibchen der Erdkröte, Bufo vulgaris, die Gonaden unter Belassung des Bidderschen Organs exstirpiert und $25 \mathrm{mg}$ Testosteron-propionsäureester („Testoviron“, $\mathrm{Schering)}$ in schwer resorbierbarer Tablettenform in den dorsalen Lymphsack implantiert. Die Implantate waren etwa nach einem halben Jahr noch in Resten erhalten.

Der Erfolg war beim Männchen die volle Ausbildung der Brunstmerkmale, schwarz gefärbte Brunstschwielen und Brunstlaute, die normalerweise erst im Frühjahr voll zur Ausprägung kommen. Die Umstimmung zum Weibchen unterblieb also. Die volle Auswirkung stellte sich nach $4-5$ Wochen ein. A.lle 6 Versuchstiere verhielten sich gleich.

Beim Weibchen (2 Versuchstiere) trat eine volle Ausbildung der typischen männlichen Geschlechtsmerkmale ein, also Brunstschwielen (s. Abb. 1, Tafel S. 136 b) und Brunstlaute nach etwa 6 Wochen.

Der Zustand des Bidderschen Organs konnte leider noch nicht festgestellt werden, da ich genötigt war, Jena im November $1949 \mathrm{zu}$ verlassen; ich hoffe jedoch, daß es mir möglich sein wird, die Versuche im Frühjahr 1950 fortführen zu können.

$1 \mathrm{~J}$. W. H a r m s, Z. Anatomie Entwicklungsgeschichte 69 [1923]; vgl. auch B. Eg gert, Z. wiss. Zool. 129, 567 [1927].

\title{
BESPRECHUNGEN
}

Zwischenmolekulare Kräfte. Herausgeg. von $\mathrm{H}$. F r i e d r i c h-Freks a, B. R a jew ski und M. S c hön. Verlag G. Braun, Karlsruhe 1949. 142 S., Preis brosch. DM 12.-.

Zwischenmolekulare Kräfte sind - wie das Vorwort betont - für viele Probleme der heutigen Biophysik, Biochemie und allgemeine Biologie einschließlich Serologie, Immunitätslehre und Virus-Forschung von erheblicher Bedeutung. Der Entschluß der Herausgeber, die anläßlich einer Biophysikalischen Arbeitstagung in Mosbach 1948 von berufener Seite gehaltenen acht Vorträge in Buchform gesammelt erscheinen zu lassen, kann daher nur begrüßt werden. Wenn sich das Buch auch in erster Linie noch an den Physiko-Chemiker, weniger direkt an den Biologen wendet, so dürfte es trotzdem in weiteren Kreisen als ein gutgelungener Überblick über den heutigen Stand des in abschließender Form noch nicht zu behandelnden Problems verdientes Interesse erwecken. Auch für den mit der Materie schon vertrauten Leser enthält das Büchlein eine Fülle von Anregungen und Hinweisen, die der Ref., der nicht zu den damaligen Tagungsteilnehmern zählte, gern und befriedigt von der Lektüre zur Kenntnis genommen hat. Der Raum verbietet es leider, auf die Vorträge im einzelnen kritisch einzugehen, hier nur ihre Titelnennung: 1. Zusammenfassender Überblick über die verschiedenen Arteń der „Zwischenmolekularen Kräfte“ (ZK), (G. B r i e g l e b, Würzburg), 2. Dispersionskräfte (T h. F ör s t e r, Göttingen), 3. Resonanzanziehung (P. J or d a n, Hamburg), 4. ZK mit besonderer Berücksichtigung der Möglichkeit von H-Brücken und Energieleitung in Proteinen (K. W i r tz, Göttingen), 5. Ionenkräfte und Dispersionskräfte bei Farbstoff-Aggregaten (G. K o r t ü m , Tübingen), 6. ZK in der statistischen Theorie der hochmolekularen Lösungen (A. M ü n s t e r, Frankfurt, Marburg), 7. ZK bei biochemischen Reaktionen (H. F r i e d rich-Freksa, Tübingen) und last not least der beachtenswerte Beitrag über 8. Konstitution und physikalisch-chemisches Verhalten von Eiweißmolekülen (G. $\mathrm{S}$ c h e i b e, München).

R. M e cke, Freiburg i. Br. 